\title{
Prevalence of Facet Effusion and Its Relationship with Lumbar Spondylolisthesis and Low Back Pain: The Wakayama Spine Study
}

This article was published in the following Dove Press journal:

Journal of Pain Research

\begin{abstract}
Kazunori Shinto,
Akihito Minamide, (D)

Hiroshi Hashizume, (D)

Hiroyuki Oka, (D) ${ }^{2}$ Ko Matsudaira, (D) ${ }^{2}$

Hiroki Iwahashi,' Yuyu Ishimoto,'

Masatoshi Teraguchi, (iD)'

Ryohei Kagotani, ' Yoshiki Asai, '

Shigeyuki Muraki, ${ }^{3}$ Toru Akune,

Sakae Tanaka, (ID ${ }^{5}$ Hiroshi Kawaguchi, ${ }^{6}$

Kozo Nakamura, ${ }^{7}$ Munehito Yoshida, ${ }^{1,8}$

Noriko Yoshimura, ${ }^{3, *}$

Hiroshi Yamada (D) ${ }^{1, *}$

'Department of Orthopaedic Surgery, Wakayama Medical University, Wakayama City, Wakayama, Japan; ${ }^{2}$ Department of Medical Research and Management for Musculoskeletal Pain, 22nd Century Medical and Research Center, Faculty of Medicine, The University of Tokyo, Bunkyo-ku, Tokyo, Japan; ${ }^{3}$ Department of Preventive Medicine for Locomotive Organ Disorders, 22nd Century Medical and Research Center, The University of Tokyo, Bunkyo-ku, Tokyo, Japan; ${ }^{4}$ National Rehabilitation Center for Persons with Disabilities, Tokorozawa City, Saitama, Japan; ${ }^{5}$ Department of Orthopaedic Surgery, The University of Tokyo, Bunkyoku, Tokyo, Japan; ${ }^{6}$ Tokyo Neurological Center, Minato-ku, Tokyo, Japan; ${ }^{7}$ Towa Hospital, Adachi-ku, Tokyo, Japan;

${ }^{8}$ Department of Orthopaedic Surgery, Sumiya Orthopaedic Hospital, Wakayama City, Wakayama, Japan
\end{abstract}

*These authors contributed equally to this work

Correspondence: Hiroshi Hashizume Department of Orthopaedic Surgery, Wakayama Medical University, Wakayama City, 8II-I Kimiidera, Wakayama City, Wakayama 64I-85I0, Japan

Tel +8I-73-44I-0645

Fax +8I-73-448-3008

Email hashizum@wakayama-med.ac.jp
Introduction: Facet effusion represents a magnetic resonance imaging finding suggesting accumulation of fluid in the facet joint, potentially predictive of lumbar spondylolisthesis and low back pain. However, its prevalence and epidemiological characteristics in the general population remain unclear, because previous studies only included patients or volunteers. The aim of the present study was to investigate the prevalence of facet effusion in the general population and to describe its potential relationship with spondylolisthesis and low back pain.

Material and methods: Our study enrolled 808 participants from the Wakayama Spine Study who underwent magnetic resonance imaging investigations in supine position. Facet effusion was defined as a measurable, curvilinear, high-intensity signal within the facet joint, closely matching that of cerebrospinal fluid on the axial T2 images. We used standing lateral radiographs to diagnose L4 spondylolisthesis.

Results: We found that the prevalence of facet effusion in the lumbar spine was $34.3 \%$, which did not differ significantly between men and women $(\mathrm{p}=0.13)$ and did not tend to increase with age, either in men $(\mathrm{p}=0.81)$ or in women $(\mathrm{p}=0.65)$. Additionally, we found no significant association between facet effusion and low back pain (odds ratio, 1.04-1.49; 95\% confidence interval, $0.57-2.64 ; \mathrm{p}=0.17-0.85$ ), or between facet effusion and L4 spondylolisthesis (odds ratio, $1.55 ; 95 \%$ confidence interval, $0.80-2.86 ; \mathrm{p}=0.17$ ). In a subset of participants with L4 spondylolisthesis, we also noted that facet effusion was not significantly associated with low back pain (odds ratio, 1.26; 95\% confidence interval, 0.37-4.27; $\mathrm{p}=0.70$ ).

Discussion: This is the first study of facet effusion employing a population-based cohort, and the findings are thus expected to accurately describe the relationship between facet effusion and low back pain in the general population. We are planning a follow-up survey of the Wakayama Spine Study cohort to clarify the natural history of facet effusion and its relationship with clinical symptoms.

Keywords: lumbar spine, facet effusion, low back pain, spondylolisthesis, epidemiology

\section{Introduction}

Low back pain (LBP) is known as a multifactorial symptom resulting from spinal sagittal imbalance, stenosis of the nerve root, compression of the cauda equina, degeneration of, or injury to various anatomical components of the spine including intervertebral discs, facet joints, and paraspinal muscles. When treating LBP, emphasis typically lies on determining the etiology, which is typically achieved using physical examination and imaging procedures, including magnetic resonance imaging (MRI). Facet effusion (FE) in an MRI finding describing the accumulation 
of fluid in the facet joint and is believed to predict LBP originating from posterior components such as facet joints. ${ }^{1-3}$ However, few studies have assessed the relationship between FE and LBP, and there are significant discrepancies among the available reports.

FE has also been reported to be related to spondylolisthesis and intervertebral instability. Spondylolisthesis describes the anterior slippage of one vertebral body onto another, and patients typically complain of LBP, leg pain, and numbness. Lumbar spondylolisthesis is commonly seen in elderly patients. Chaput et $\mathrm{al}^{4}$ first described FE as a predictive factor of spondylolisthesis on radiography. Later, several authors reported a positive correlation between the amount of FE and the extent of segmental motion at the inferior intervertebral level in patients with spondylolisthesis. ${ }^{5-7}$ According to such reports, ${ }^{5-9}$ FE may reflect the spinal instability following segmental motion of the vertebrae, which, in the opinion of most spine surgeons, leads to LBP. Thus, in patients with degenerative spondylolisthesis and findings of FE, treatment involves spinal fusion in addition to decompression, as $\mathrm{FE}$ is thought to be strongly related to LBP.

However, previous studies only included patients or volunteers, ${ }^{1-11}$ suggesting selection bias and, consequently, limited applicability of their findings to the general population. Therefore, a population-based study is essential for clarifying the prevalence of FE and its potential relationship with LBP or spondylolisthesis.

In the present study, we first aimed to evaluate the epidemiological background of FE in a cohort of the general population, and then to investigate the potential association between FE and LBP or spondylolisthesis.

\section{Materials and Methods}

This study was conducted in accordance with the Declaration of Helsinki and the study design was approved by the Ethics Committee of the Wakayama Medical University. All volunteers provided written informed consent for participation.

\section{Participants}

The Wakayama Spine Study is a population-based survey regarding degenerative spinal diseases, ${ }^{12-16}$ instituted as a sub-cohort of the Research on Osteoarthritis/osteoporosis Against Disability (ROAD) Study in Japan. ${ }^{17,18}$ ROAD is a nationwide, prospective study of bone and joint disease and consists of a population-based cohort originating from three regions, each with different characteristics: an urban region in Tokyo, a mountainous region in Wakayama, and a coastal region in Wakayama. The participants were enrolled in a given cohort based on their listings in the residence registry. The other inclusion criteria were the ability to travel to the survey site, report data, understand instructions, and sign the informed consent form. No exclusion criteria were applied.

The third clinical evaluation of the ROAD Study was held in 2012 for the residents from the mountainous region of Wakayama, and in 2013 for the residents from the coastal region of Wakayama. Of the ROAD Study participants who attended the third clinical evaluation, 1575 volunteers (718 residents of the mountainous region, 857 in the coastal region) participated in the second survey of the Wakayama Spine Study. Unfortunately, MRI could only be conducted for residents from the coastal area (857 participants). Of these, 42 participants with incomplete MRI records, 6 participants with MRI unsuitable for evaluation of the facet joints, and one participant who had previously undergone posterior lumbar fusion were excluded from the present analysis. Finally, 808 subjects were enrolled in the present study (Figure 1).

Board-certified orthopedic surgeons with ample experience interviewed the participants regarding the symptoms. The following question was used to assess the presence of LBP: "Have you experienced LBP on most days during the past month, in addition to now?" Participants who answered "yes" were defined as having LBP, according to the practice reported in previous studies. ${ }^{19-23}$

\section{Plain Radiographic Evaluation}

Participants basically underwent radiographic evaluation. Standing lateral radiographs of the whole spine and pelvis were taken using a 40-inch film. Each radiograph was aligned such that the edge of the film was taken as the reference for the vertical axis. As described in detail elsewhere, ${ }^{24}$ the participants were instructed to stand in a comfortable position, with the hips and knees fully extended, the arms flexed, and the hands resting on supports at the level of their shoulders. L4 spondylolisthesis was diagnosed if anterior slippage $\geq 3 \mathrm{~mm}$ was noted for the L4 vertebra. ${ }^{25}$

\section{MRI Evaluation}

A mobile MRI unit (Achieva 1.5 T; Philips Medical Systems, Best, the Netherlands) was used. Whole-spine MRI was performed for all participants on the same day as the rest of the clinical examination. The participants lay supine during the MRI examination, and those with 
The third visit of the ROAD study (2012-2013)

The participants were recruited from three communities: an urban region, a mountainous region, and a coastal

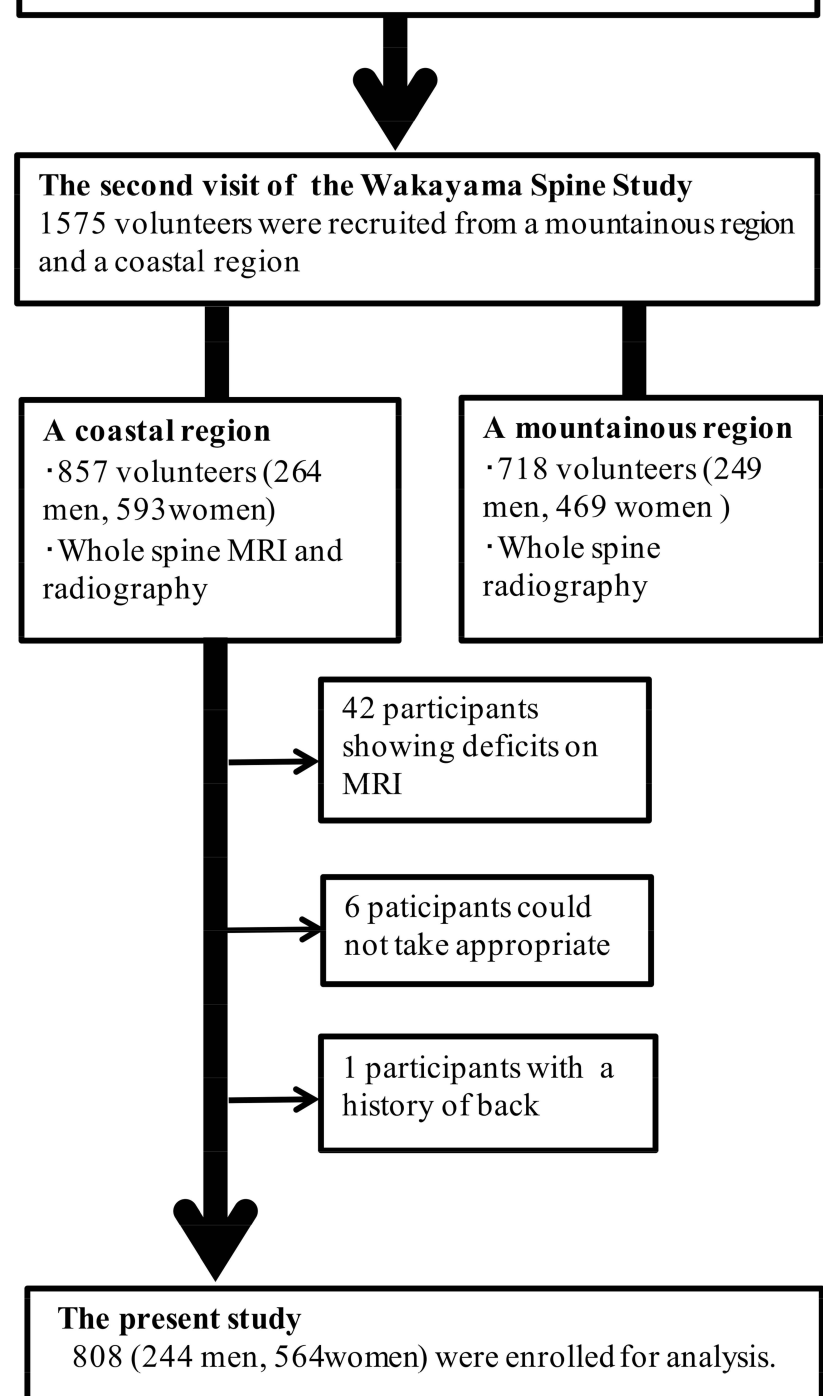

Figure I Flow diagram depicting the study enrollment strategy. Participants for the present study were recruited from among the residents of the Wakayama coastal region who attended the 2013 visit for clinical evaluation, as a part of the Research on Osteoarthritis/osteoporosis Against Disability (ROAD) Study.

rounded back used triangular pillows under their heads and knees. The imaging protocol included sagittal T2-weighted fast spin-echo imaging (repetition time, $3000 \mathrm{~ms} / \mathrm{echo}$; echo time, $120 \mathrm{~ms}$; and field of view, $270 \times 270 \mathrm{~mm}$ ) and axial T2-weighted fast spin-echo imaging (repetition time, $2100 \mathrm{~ms} / \mathrm{echo}$; echo time, $100 \mathrm{~ms}$; and field of view, $180 \times 180 \mathrm{~mm}$ ). Sagittal images were taken for the entire spine, while axial images were obtained for each lumbar intervertebral level (L1/2-L5/S1), parallel to the vertebral endplates. Total scan time was between 25 and 30 mins.
Facet effusion was defined as a clinically measurable $(>$ or $=1 \mathrm{~mm})$, curvilinear, high-intensity signal within the facet joint, closely matching that of cerebrospinal fluid on the axial T2 images. ${ }^{4}$ Patients were defined as showing FE at a given intervertebral level if $\mathrm{FE}$ was noted in one or both facet joints at that intervertebral level (Figure 2).

\section{Statistical Analysis}

The participants' demographic characteristics and prevalence of FE were summarized using descriptive statistics. Chi-square tests were used to analyze categorical data, whereas Student's $t$-tests were used to compare parametric continuous variables between groups of male and female participants. The Cochran-Armitage trend test was used to calculate the statistical significance of the prevalence of FE trend across age-based groups.

The relationship between intervertebral level and prevalence of $\mathrm{FE}$ was analyzed using the chi-square test followed by residual analysis to determine the statistical significance of cells in the tables. Cells with adjusted standardized residuals $>1.96$ were considered to indicate significantly higher prevalence than expected, whereas cells with residuals $<-1.96$ were considered to indicate significantly lower prevalence than expected.

Multivariable logistic regression models were used to determine the relationship between FE and low back pain

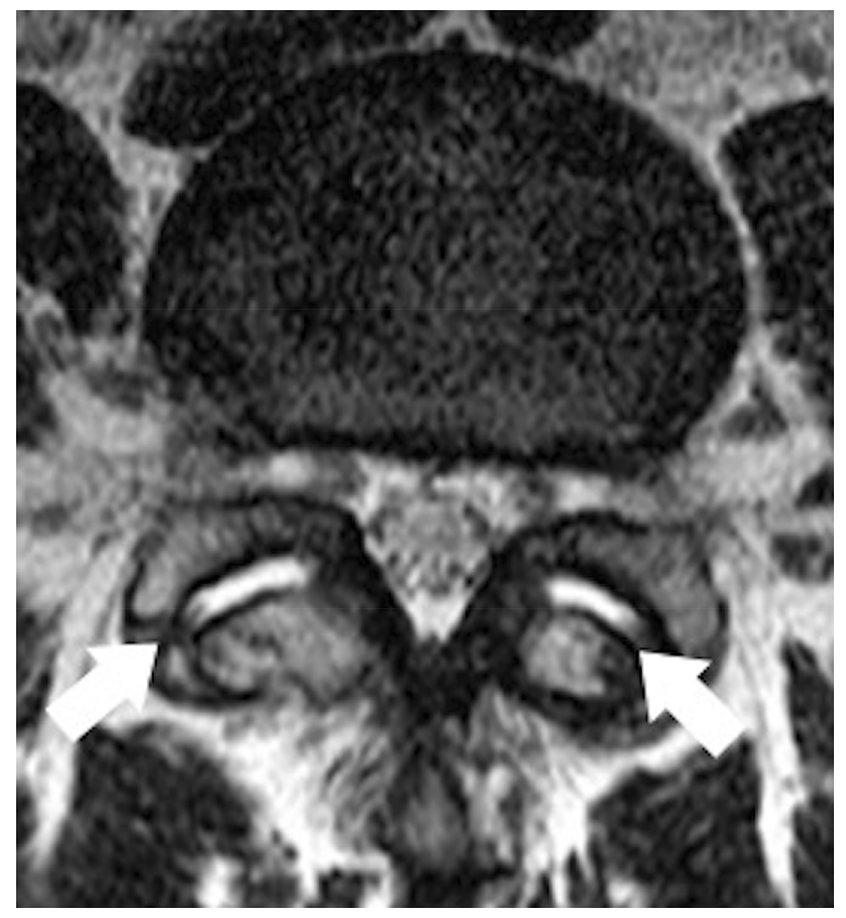

Figure 2 Representative magnetic resonance image showing facet effusion (arrows). 
after adjusting for age, sex, and body mass index (BMI). Five models were analyzed, one for each of five disk levels (L1/2, L2/3, L3/4, L4/5, L5/S). A total of 5 participants were excluded from this analysis because they had not answered the question regarding LBP.

Next, the relationship between L4 spondylolisthesis and FE at L4/5 was assessed using multivariable logistic regression models adjusted for age, sex, and BMI; this analysis included eligible 793 participants, as 12 participants did not undergo the sagittal spinal radiograph, and 3 participants had poor radiographs, insufficient to assess spondylolisthesis. Furthermore, the 90 participants with L4 spondylolisthesis were stratified for examining the relationship between LBP and $\mathrm{FE}$ at $\mathrm{L} 4 / 5$, which has been often discussed in relation to the fusion surgery. A multivariable logistic regression model adjusted for age, sex, and BMI was tested again.

All statistical analyses were performed using JMP Pro version 12 (SAS Institute Inc., Cary, North Carolina, USA). A p-value of 0.05 was considered to indicate a significant difference.

\section{Results}

Table 1 provides an overview of the characteristics of the 808 participants included in this study, including demographic measurements and prevalence of FE, L4 spondylolisthesis, and LBP. The overall prevalence of FE (ie, at any intervertebral level of the lumbar spine) was $34.3 \%$, with no significant difference between male and female participants (men, 38.1\%; women, 32.6\%). The prevalence of L4 spondylolisthesis and LBP was $11.4 \%$ and $38.7 \%$, respectively.

No linear trend in the prevalence of FE was observed across age strata, either in male or in female participants (Cochran Armitage trend test: $\mathrm{p}=0.81$ for men, $\mathrm{p}=0.65$ for women; Table 2).

Table 3 summarizes the prevalence of FE across the five intervertebral levels of the lumbar spine. In men and women, respectively, levels L2/3, L3/4 and L4/5 showed higher prevalence of FE, although they were not statistically significant.

On multiple logistic regression analysis adjusted by sex, age, and BMI, no significant association was noted between LBP and FE at any particular intervertebral level (Table 4).

Furthermore, multiple logistic regression analysis after adjustment for age, sex, and BMI revealed no significant association between L4 spondylolisthesis and presence of $\mathrm{FE}$ at $\mathrm{L} 4 / 5 \quad(\mathrm{n}=793$; odds ratio, $1.53 ; 95 \%$ confidence interval, $0.78-2.81 ; \mathrm{p}=0.2049)$. No significant association between FE at L4/5 and LBP was noted in the stratified participants with L4 spondylolisthesis $(\mathrm{n}=90$; odds ratio, $1.26 ; 95 \%$ confidence interval, $0.37-4.27 ; \mathrm{p}=0.70)$.

\section{Discussion}

We provide the first report to describe the prevalence of FE in a population-based cohort. The overall prevalence of FE was $34.3 \%$, which did not differ significantly between males and females, and did not tend to increase with age. Furthermore, we found no significant association between

Table I Characteristics of Residents from the Coastal Area of Wakayama, Who Underwent Magnetic Resonance Imaging as Part of the Wakayama Spine Study

\begin{tabular}{|c|c|c|c|c|}
\hline & Overall & Men & Women & p-value \\
\hline No. of participants & 808 & 244 & 564 & \\
\hline \multicolumn{5}{|l|}{ Demographic characteristic } \\
\hline Age, years & $63.5 \pm 13.1$ & $63.1 \pm 14.0$ & $63.7 \pm 12.7$ & 0.54 \\
\hline Height $\mathrm{cm}$ & $157.4 \pm 8.97$ & $166.8 \pm 6.73$ & $153.3 \pm 6.38$ & $<0.0001$ \\
\hline Weight, kg & $57.2 \pm 11.4$ & $66.6 \pm 10.8$ & $53.1 \pm 8.97$ & $<0.0001$ \\
\hline Body mass index, $\mathrm{kg} / \mathrm{m}^{2}$ & $23.0 \pm 3.65$ & $23.9 \pm 3.50$ & $22.6 \pm 3.65$ & $<0.0001$ \\
\hline \multicolumn{5}{|l|}{ Radiographic parameters } \\
\hline Prevalence of facet effusion & $277 / 808(34.3 \%)$ & $93 / 244$ (38.1\%) & $184 / 564(32.6 \%)$ & 0.13 \\
\hline Prevalence of L4 spondylolisthesis & $90 / 790$ (II.4\%) & $|8 / 24|(7.47 \%)$ & $72 / 549$ (13.1\%) & 0.02 \\
\hline Prevalence of low back pain & $311 / 803(38.7 \%)$ & 93/242 (38.4\%) & $218 / 56 \mid(38.9 \%)$ & 0.91 \\
\hline
\end{tabular}

Notes: Data are presented as mean \pm standard deviation or as number (percentage). The $\mathrm{p}$-values were determined using a Student's $t$-test or a Chi-square test. 
Table 2 Prevalence of Facet Effusion Across Age Strata Among 808 Participants of the Wakayama Spine Study

\begin{tabular}{|l|l|l|l|}
\hline Age Strata & Male $(\mathbf{n = 2 4 4 )}$ & Female $(\mathbf{n}=564)$ & p-value \\
\hline$<50$ years & $15 / 39(38.5 \%)$ & $19 / 72(26.4 \%)$ & 0.19 \\
$50-59$ years & $19 / 47(40.4 \%)$ & $44 / 125(35.2 \%)$ & 0.53 \\
$60-69$ years & $26 / 80(32.5 \%)$ & $56 / 166(33.7 \%)$ & 0.85 \\
$\geq 70$ years & $33 / 78(42.3 \%)$ & $65 / 201(32.3 \%)$ & 0.11 \\
\hline
\end{tabular}

Notes: Data are presented as number (percentage). A participant was defined as showing facet effusion if corresponding magnetic resonance findings were noted in more than one intervertebral level of the lumbar spine.

Table 3 Prevalence of Facet Effusion Across the Five Intervertebral Levels of the Lumbar Spine Among 808 Participants of the Wakayama Spine Study

\begin{tabular}{|l|l|l|l|}
\hline Level & Male $(\mathbf{n}=244)$ & Female $(\mathbf{n}=564)$ & p-value \\
\hline $\mathrm{LI} / 2$ & $16(6.6 \%)$ & $28(5.0 \%)$ & 0.35 \\
$\mathrm{~L} 2 / 3$ & $29(11.9 \%)$ & $62(11.0 \%)$ & 0.71 \\
$\mathrm{~L} 3 / 4$ & $41(16.8 \%)$ & $66(11.7 \%)$ & 0.049 \\
$\mathrm{~L} 4 / 5$ & $31(12.7 \%)$ & $69(12.2 \%)$ & 0.85 \\
$\mathrm{~L} 5 / \mathrm{S}$ & $17(7.0 \%)$ & $35(6.2 \%)$ & 0.69 \\
\hline
\end{tabular}

Note: Data are presented as number (percentage).

Table 4 Association Between Low Back Pain and Facet Effusion at Each of the Five Intervertebral Levels of the Lumbar Spine, Obtained Based on Magnetic Resonance Imaging and Questionnaire Data from 803 Participants of the Wakayama Spine Study

\begin{tabular}{|l|l|l|l|}
\hline Level & OR & $95 \% \mathbf{~ C I}$ & p-value \\
\hline $\mathrm{LI} / 2$ & 1.08 & $0.57-2.01$ & 0.80 \\
$\mathrm{~L} 2 / 3$ & 1.32 & $0.85-2.06$ & 0.22 \\
$\mathrm{~L} 3 / 4$ & 1.11 & $0.73-1.69$ & 0.62 \\
$\mathrm{~L} 4 / 5$ & 1.04 & $0.67-1.6 \mathrm{I}$ & 0.85 \\
$\mathrm{~L} 5 / \mathrm{S}$ & 1.49 & $0.84-2.64$ & 0.17 \\
\hline
\end{tabular}

Notes: Data were obtained via multivariable logistic regression analysis, after adjustment for age, sex, and body mass index.

Abbreviations: OR, odds ratio; $\mathrm{Cl}$, confidence interval.

the presence of FE and LBP, either in the general population or even in volunteers with spondylolisthesis. In this study, we analyze more than 800 participants, so we consider statistical power to be sufficient. Further investigations are warranted to clarify the natural history of FE and its relationship with clinical symptoms of the lumbar spine. In this direction, we plan a follow-up longitudinal survey of the Wakayama Spine Study cohort, including additional radiographic investigations and clinical evaluation.

The prevalence of FE noted in our study is lower than the previously quoted values, which ranged between $46 \%$ and $86 \%{ }^{1,2}$ This discrepancy regarding the prevalence of FE may be related to the composition of the study population.
Specifically, previous studies ${ }^{1,2}$ focused on patients or volunteers, whereas the present study used a population-based cohort. Ethnic differences may also play a role.

We noted that the prevalence of FE did not increase with age. We believe this observation may be related to the fact that FE does not represent an irreversible finding on MRI. Kirkaldy-Willis ${ }^{26}$ divided the degenerative process in the lumbar spine into the following three pathological stages. In the initial stage, dysfunction is reflected as minimal changes in anatomical pathology. In the intermediate stage, there are changes related to spinal instability and disc degeneration; specifically, the ligaments and posterior capsule of facet joints are lax, which results in abnormal range of movement characterized as lumbar segmental instability. The last stage consists of restabilization of the joint due to progressively decreased movement as a result of fibrosis and osteophyte formation in the facet joints. In fact, some authors suggested that effusion width is representative of segmental intervertebral instability, ${ }^{5-9}$ with one report concluding that effusion is decreased in the restabilized motion segment. ${ }^{7}$

Although we had originally hypothesized that FE would be associated with LBP, our results suggested no significant association. Few reports have described the

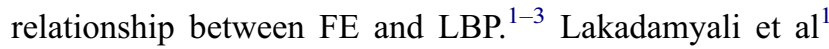
and Manika et $\mathrm{al}^{2}$ hypothesized that FE was indicative of LBP caused by facet joint disorders, and indeed found that FE was significantly more prevalent in patients with LBP. Specifically, Lakadamyali et al ${ }^{1}$ investigated the association between LBP and MRI findings in 372 patients with LBP and 249 healthy volunteers. They found that the prevalence of FE in patients with LBP (85.5\%) was significantly higher than that among volunteers (45.8\%), and therefore suggested that FE may represent a cause of LBP or a manifestation of the cause of LBP. Manika et $\mathrm{al}^{2}$ also investigated the relationship between LBP and FE in 75 patients with LBP and 75 controls and found a lower prevalence of $\mathrm{FE}$ among the controls (75\%) than among the patients with LBP (85\%). However, they noted that FE was commonly seen among the controls and concluded that FE did not represent a sufficiently specific finding for diagnosing LBP. Suri et $\mathrm{al}^{3}$ reviewed the clinical records of 64 patients with LBP and noted that the presence of FE at any level was significantly associated with LBP on the same side of the lower back. In the present study, we did not find a significant association between FE and LBP. Our results suggest that FE may represent a common 
degenerative finding in elderly individuals, regardless of whether or not they present with LBP.

Despite our original assumption, we found that FE was not associated with degenerative spondylolisthesis. More importantly, we found no significant association between FE and LBP in participants with spondylolisthesis. To our knowledge, few reports have described the relationship between FE and LBP in such patients. Lattin et al ${ }^{11}$ proposed that $\mathrm{FE}$ alone need not be an indication for adding fusion to decompression in the treatment of spondylolisthesis, because no significant difference in postoperative outcome was noted between decompression alone and decompression with fusion. Nevertheless, because there is a prevalent concept that FE is associated with LBP, spinal fusion is generally added in the management of patients with FE. Our results suggest that the decision to add spinal fusion merely based on the presence of FE should be avoided, and alternative surgical options should be considered.

The present study has several limitations. First, this was a cross-sectional study, and thus we could not clarify the natural history of FE or causal relationship between FE and LBP. Nevertheless, the Wakayama Spine Study is a longitudinal survey, and we expect that further study will help elucidate these points. Second, the participants were recruited from a single area, and there is a possibility that the study sample may not represent the general population. To assess the possibility of sampling-related bias, we compared the anthropometric data obtained for the participants of this study against those reported for the general Japanese population, ${ }^{27}$ and noted a significant difference regarding BMI for both men (23.9 \pm 3.50 vs. $\left.24.0 \pm 3.36 \mathrm{~kg} / \mathrm{m}^{2} ; \mathrm{p}=0.01\right)$ and women $\left(22.6 \pm 3.65\right.$ vs. $\left.22.3 \pm 3.69 \mathrm{~kg} / \mathrm{m}^{2} ; \mathrm{p}<0.05\right)$. Therefore, it is possible that the prevalence of FE and LBP noted among the participants enrolled in the present study might differ from the prevalence of FE and LBP among the general Japanese population. However, we believe that our findings from the Wakayama Spine Study describing the relationship between FE and LBP can indeed be generalized. Third, we could not confirm whether FE was indeed associated with spinal segmental instability because we did not examine flexion-extension radiographs of the lumbar spine. Finally, in the multivariable logistic regression analyses, we did not control for other degenerative findings potentially associated with FE, such as osteoarthritis of the facet joints, because we did not have such data. Future studies should consider such degenerative MRI findings.

\section{Conclusion}

We provide the first report to describe the prevalence of FE in a population-based cohort. The overall prevalence of FE was $34.3 \%$, which did not differ significantly between males and females, and did not tend to increase with age. Furthermore, we found no significant association between the presence of FE and LBP, either in the general population or even in the stratified subgroup with spondylolisthesis. Further investigations are warranted to clarify the natural history of FE and its relationship with clinical symptoms of the lumbar spine. In this direction, we plan a follow-up longitudinal survey of the Wakayama Spine Study cohort, including additional radiographic investigations and clinical evaluation.

\section{Funding}

This study was supported by H23-Choujyu-002 (Director, TA), H-25-Choujyu-007 (Director, NY), H25-Nanchitou (Men)-005 (Director, ST), 201417014A (Director, NY), and H22-Choujyu-Wakate-007 (Director, SM) from the Ministry of Health, Labour and Welfare, URL:http://www.mhlw.go.jp/; a Grant-in-Aid for Scientific Research (B26293139, B23390172 to NY, B2629333, C20591774 to SM, C26462249 to HH, C25462305 to HY) and a Grant-in-Aid for Young Researcher (B25860448 to YI, B26861286 to MT, B26860419 to RK), and Grant-in-Aid for Challenging Exploratory Research (15K15219 to NY, 26670307 to SM, 24659666 to HO, 25670293 to TA) of JSPS KAKENHI grant, URL:https://www.jsps.go.jp/j-grantsinaid/; a Grant from the Japanese Orthopaedics and Traumatology Foundation, Inc. (No. 287) to MT, URL:http://jotf.jp/invitation.html; and Collaborating Research with NSF 08033011-00262 (Director, NY) from the Ministry of Education, Culture, Sports, Science and Technology in Japan, URL:http://www. mext.go.jp/english/. This study also was supported by grants from the Japan Osteoporosis Society (NY, SM, HO, and TA), URL:http://www.josteo.com/ja/index.html, a grant from JA Kyosai Research Institute (HO), URL:http://www.jkri.or.jp/, grants from Mitsui Sumitomo Insurance Welfare Foundation (SM), URL:http://www.ms-ins.com/welfare/index.htm, and research aid from the Japanese Orthopaedic Association (JOA-Subsidized Science Project Research 2006-1 \& 20102; Director, HK), URL:https://www.joa.or.jp/english/english frame.html. The funders had no role in study design, data collection and analysis, decision to publish, or preparation of the manuscript. 


\section{Disclosure}

Dr Hiroshi Hashizume reports grants from JSPS kakenhi during the conduct of the study. Dr Hiroyuki Oka reports grants from teijin pharma limited, grants from Pfizer Inc., and personal fees from AYUMI Pharmaceutical Corporation, Nippon Zoki Pharmaceutical Co., Ltd., ONO Pharmaceutical Co., Ltd., Shionogi \& Co., Ltd. and Kaken Pharmaceutical Co., Ltd, outside of the submitted work. The author reports no other conflicts of interest in this work.

\section{References}

1. Lakadamyali H, Tarhan NC, Ergun T, Cakir B, Agildere AM. STIR sequence for depiction of degenerative changes in posterior stabilizing elements in patients with lower back pain. AJR Am J Roentgenol. 2008;191(4):973-979. doi:10.2214/AJR.07.2829

2. Mainka T, Lemburg SP, Heyer CM, Altenscheidt J, Nicolas V, Maier C. Association between clinical signs assessed by manual segmental examination and findings of the lumbar facet joints on magnetic resonance scans in subjects with and without current low back pain: a prospective, single-blind study. Pain. 2013;154 (9):1886-1895. doi:10.1016/j.pain.2013.06.018

3. Suri P, Dharamsi AS, Gaviola G, Isaac Z. Are facet joint bone marrow lesions and other facet joint features associated with low back pain? A pilot study. PM R. 2013;5(3):194-200. doi:10.1016/j. pmrj.2012.09.002

4. Chaput C, Padon D, Rush J, Lenehan E, Rahm M. The significance of increased fluid signal on magnetic resonance imaging in lumbar facets in relationship to degenerative spondylolisthesis. Spine (Phila Pa 1976). 2007;32(17):1883-1887. doi:10.1097/BRS.0b013e318113271a

5. Cho BY, Murovic JA, Park J. Imaging correlation of the degree of degenerative L4-5 spondylolisthesis with the corresponding amount of facet fluid. J Neurosurg Spine. 2009;11(5):614-619. doi:10.3171/ 2009.6.SPINE08413

6. Lattig F, Fekete TF, Grob D, Kleinstück FS, Jeszenszky D, Mannion AF. Lumbar facet joint effusion in MRI: a sign of instability in degenerative spondylolisthesis? Eur Spine J. 2012;21(2):276-281. doi:10.1007/s00586-011-1993-1

7. Oishi Y, Murase M, Hayashi Y, Ogawa T, Hamawaki J. Smaller facet effusion in association with restabilization at the time of operation in Japanese patients with lumbar degenerative spondylolisthesis. J Neurosurg Spine. 2010;12(1):88-95. doi:10.3171/2009.7.SPINE08908

8. Kuhns BD, Kouk S, Buchanan C, et al. Sensitivity of magnetic resonance imaging in the diagnosis of mobile and nonmobile L4-L5 degenerative spondylolisthesis. Spine J. 2015;15(9):1956-1962. doi:10.1016/j.spinee.2014.08.006

9. Even JL, Chen AF, Lee JY. Imaging characteristics of "dynamic" versus "static" spondylolisthesis: analysis using magnetic resonance imaging and flexion/extension films. Spine J. 2014;14(9):1965-1969. doi:10.1016/j.spinee.2013.11.057

10. Rihn JA, Lee JY, Khan M, et al. Does lumbar facet fluid detected on magnetic resonance imaging correlate with radiographic instability in patients with degenerative lumbar disease? Spine (Phila Pa 1976). 2007;32(14):1555-1560. doi:10.1097/BRS.0b013e318067dc55

11. Lattin F, Fekete TF, Kleinstück FS, Porchet F, Jeszenszky D, Mannion AF. Lumbar facet effusion on MRI as a sign of unstable degenerative spondylolisthesis: should it influence the treatment decision? J Spinal Disord Tech. 2015;28(3):95-100. doi:10.1097/ BSD.0b013e318269c261
12. Nagata K, Yoshimura N, Muraki S, et al. Prevalence of cervical cord compression and its association with physical performance in a population-based cohort in Japan: the Wakayama Spine Study. Spine (Phila Pa 1976). 2012;37(2):1892-1898. doi:10.1097/ BRS.0b013e31825a2619

13. Teraguchi M, Yoshimura N, Hashizume H, et al. Prevalence and distribution of intervertebral disc degeneration over the entire spine in a population-based cohort: the Wakayama Spine Study. Osteoarthritis Cartilage. 2014;22(1):104-110. doi:10.1016/j.joca.2013.10.019

14. Ishimoto Y, Yoshimura N, Muraki S, et al. Associations between radiographic lumbar spinal stenosis and clinical symptoms in the general population: the Wakayama Spine Study. Osteoarthritis Cartilage. 2013;21(6):783-788. doi:10.1016/j.joca.2013.02.656

15. Nagata K, Yoshimura N, Hashizume H, et al. The prevalence of cervical myelopathy among subjects with narrow cervical spinal canal in a population-based magnetic resonance imaging study: the Wakayama Spine Study. Spine J. 2014;14(12):2811-2817. doi:10.1016/j.spinee.2014.03.051

16. Teraguchi M, Yoshimura N, Hashizume $\mathrm{H}$, et al. The association of combination of disc degeneration, end plate signal change, and Schmorl node with low back pain in a large population study: the Wakayama Spine Study. Spine J. 2015;15(4):622-628. doi:10.1016/j.spinee.2014.11.012

17. Yoshimura N, Muraki S, Oka H, Kawaguchi H, Nakamura K, Akune T. Cohort profile: Research on Osteoarthritis/osteoporosis Against Disability (ROAD) study. Int $J$ Epidemiol. 2010;39 (4):988-995. doi:10.1093/ije/dyp276

18. Yoshimura N, Muraki S, Oka H, et al. Prevalence of knee osteoarthritis, lumbar spondylosis, and osteoporosis in Japanese men and women: the research on osteoarthritis/osteoporosis against disability study. J Bone Miner Metab. 2009;27(5):620-628. doi:10.1007/ s00774-009-0080-8

19. Muraki S, Oka H, Akune T, et al. Prevalence of radiographic lumbar spondylosis and its association with low back pain in elderly subjects of population-based cohorts: the ROAD study. Ann Rheum Dis. 2009;68(9):1401-1406. doi:10.1136/ard.2007.087296

20. Muraki S, Akune T, Oka H, et al. Impact of knee and low back pain on health-related quality of life in Japanese women: the Research on Osteoarthritis against Disability (ROAD). Mod Rheumatol. 2010;20 (5):444-451. doi:10.3109/s10165-010-0307-5

21. Muraki S, Akune T, Oka H, et al. Health-related quality of life in subjects with low back pain and knee pain in a population-based cohort study of Japanese men: the research on osteoarthritis against disability study. Spine (Phila Pa 1976). 2011;36(16):1312-1319. doi:10.1097/BRS.0b013e3181 fa60d1

22. Muraki S, Akune T, Oka H, et al. Incidence and risk factors for radiographic lumbar spondylosis and lower back pain in Japanese men and women: the ROAD study. Osteoarthritis Cartilage. 2012;20 (7):712-718. doi:10.1016/j.joca.2012.03.009

23. Dionne CE, Dunn KM, Croft PR, et al. A consensus approach toward the standardization of back pain definitions for use in prevalence studies. Spine (Phila Pa 1976). 2008;33(1):95-103. doi:10.1097/ BRS.0b013e31815e7f94

24. Zhu Z, Xu L, Zhu F, et al. Sagittal alignment of spine and pelvis in asymptomatic adults: norms in Chinese populations. Spine (Phila Pa 1976). 2014;39(1):E1-E6. doi:10.1097/BRS.0000000000000022

25. Horikawa K, Kasai Y, Yamakawa T, Sudo A, Uchida A. Prevalence of osteoarthritis, osteoporotic vertebral fractures, and spondylolisthesis among the elderly in a Japanese village. J Orthop Surg (Hong Kong). 2006;14(1):9-12. doi:10.1177/230949900601400103

26. Kirkaldy-Willis WH, Farfan HF. Instability of the lumbar spine. Clin Orthop Relat Res. 1982;165:110-123.

27. Ministry of Health, Labour and Welfare. The report of the national health and nutrition survey. 2013. Available from: http://www.mhlw.go.jp/bunya/ kenkou/eiyou/dl/h25-houkoku-05.pdf. Accessed November 6, 2016. 


\section{Publish your work in this journal}

The Journal of Pain Research is an international, peer reviewed, open access, online journal that welcomes laboratory and clinical findings in the fields of pain research and the prevention and management of pain. Original research, reviews, symposium reports, hypothesis formation and commentaries are all considered for publication. The manuscript management system is completely online and includes a very quick and fair peer-review system, which is all easy to use. Visit http:// www.dovepress.com/testimonials.php to read real quotes from published authors. 